\title{
Assessing Countries Sustainability: A Group Multicriteria Decision Making Methodology Approach
}

\author{
Roberto Castaneda ${ }^{1}$, Pilar Arroyo ${ }^{2} \&$ Lourdes Loza $^{3}$ \\ ${ }^{1}$ Engineering and Science School, Tecnologico de Monterrey, Estado de Mexico, Mexico \\ ${ }^{2}$ EGADE Business School, Tecnologico de Monterrey, Estado de Mexico, Mexico \\ ${ }^{3}$ Facultad de Ingenieria, Universidad Autonoma del Estado de Mexico, Mexico \\ Correspondence: Roberto Castaneda, Engineering and Science School, Tecnologico de Monterrey, Estado de \\ Mexico, Mexico. E-mail: A01510084@itesm.mx
}

Received: April 22, 2020 Accepted: May 23, 2020 Online Published: May 26, 2020

doi:10.5539/jms.v10n1p174 URL: https://doi.org/10.5539/jms.v10n1p174

\begin{abstract}
Sustainability is a complex and abstract concept. However, policy-makers and representatives of global and regional associations need to assess and track the sustainable development of countries and regions to define a sustainability strategic path. The objective of this research is to propose and validate a methodology to define a simple but proper sustainability index that serves as a proxy for the identification of the segments of most and least advanced countries according to their achievement of the sustainable development goals defined by the United Nations (UN). Several well-known quantitative methodologies are used to first define a summarized index of sustainable development. Second, multicriteria decision-making methods are applied to determine the relative importance of the elements or dimensions comprising the sustainability concept. Then, the simulated judgments of a group of experts is used to compute a group weight vector by applying the Fuzzy Analytic Hierarchy Process (FAPH). Different aggregation methods are used to compute the importance that decision-makers assign to the several dimensions of sustainability. Finally, segments of countries generated with the clustering algorithm k-means are rated to identify sustainability benchmark segment(s) and groups of countries in need of support to attain the UN sustainability goals.
\end{abstract}

Keywords: sustainable development, group multicriteria decision making methods, fuzzy analytic hierarchical process, latent variables, segmentation

\section{Introduction}

Sustainable Development (SD) has become a topic of increasing interest to international agencies, governmental and non-governmental organizations (NGOs), private enterprises, academics, and society in general. The Brundtland Commission (1988) briefly defines SD as "the ability to make development sustainable to ensure that it meets the needs of the present without compromising the ability of future generations to meet their own needs". Based on this definition, three key pillars or dimensions of SD are identified: economic growth, social wellbeing, and environmental protection. Each of these SD dimensions comprises multiple components or sub-dimensions which are inferred through measurable indicators. For example, social sustainability includes the accessibility to health services, respect for human rights, quality education, and freedom. Economic growth comprises tangible indicators such as gross domestic product (GDP), GDP per person, income distribution, productivity, and entrepreneurial activity. Finally, environmental sustainability involves elements such as biodiversity, consumption of non-renewable resources, land conservation, and amount of greenhouse emissions.

The Millennium Development Goals (MDGs) defined in September 2000 by the United Nations (UN) in collaboration with world leaders set the basis of a global partnership with the aims to reduce poverty, strengthen equity, and human rights while ensuring environmental sustainability. Over 140 countries committed to achieve the MDG by 2030, but only 18 countries have explicitly considered the MDG in their economic budgets (United Nations [UN], 2019). The MDG set up broad objectives for the UN members states, however, they are mainly focused on increasing the living standards of the population of developing countries. The successors of the MDG are the Sustainable Development Goals (SDG). These 17 goals (the MDG consists of only 8 goals), the SDG set more ambitious goals that complement and reinforce the MDGs by considering multiple aspects of sustainable 
growth which drive the transformative actions required to assure an inclusive, sustainable and resilient future for people (UN, 2020). The SDGs can be divided into three broad categories: 1) extensions of MDGs, 2) inclusiveness, infrastructure and industrialization, and 3) environmental protection and sustainable urbanization.

The Sustainable Development Report (UN, 2019) presents national and regional SDG indexes and Dashboards that summarize the assessment of countries based on the distance to the SDG targets. However, the elusiveness of the sustainability concept and the interdependence of its components contributes to the imprecision of these global indexes and other indexes and indicators that have been proposed to assess SD (Van de Kerk \& Manuel, 2008). Campagnolo, Eboli, Farnia and Carraro (2018b) and Mensah (2019) also noticed that the limited availability of data for all countries, and the interrelationships between the SD dimensions, represent a problem to Public Administrators who must monitor the sustainability progress of countries and regions to define strategies that satisfy the expectations of different stakeholders (e.g., local governments and global organizations). Mensah (2019) argued that further clarification of the SD concept, as well as the identification of key indicators associated with its three main dimensions can help to develop a better global SD index.

Sustainability is an abstract concept or latent variable whose magnitude needs to be assessed with the use of tangible and measurable indicators. Under this perspective, measuring SD requires identifying the dimensions that comprise the concept and to define a minimum number of indicators related with each dimension. The resulting SD index is a proxy variable of sustainable development and its validity depends on the clarity of the concept definition, how well it is distinguished from other concepts (e.g., economic development vs. sustainability), and the extent to what indicators used to measure SD are logically and highly correlated to its dimensions. In certain cases, the sub-dimensions or components of the main dimensions comprising a concept are also latent variables that need to be finally expressed in terms of observable indicators (Bauldry, Bollen, \& Adair, 2015). Due to the large number of indicators that may be associated with the latent variables, the identification of key ones helps to overcome the difficulty of data availability and simplifies the measurement model proposed to operationalize the variable.

The identification of regions that face similar challenges in attaining the SDG is relevant to international and local organizations to identify what regions require major attention, monitor their progress, and allocate resources to decreasing the distance to the SDG targets at the same rate as other regions. The objective of this research is to propose and validate a methodology to define a simple but appropriate sustainability index, that serves as a proxy for the identification of segment(s) of most and least advanced countries in terms of the achievement of the sustainable development goals defined by the United Nations. The proposed methodology is based on well-known quantitative methods to first define a brief but meaningful SD index that represents the intuitive and abstract dimensions of sustainable development. Then, countries are rated and classified according to this summarized SD index. And finally, the multidisciplinary perspective of experts is taken into consideration to identify the segment(s) of countries that according to the decision-makers responsible for monitoring sustainable development, require(s) more attention.

This work is organized as follows: in the second section following this introduction, a review of the sustainable indexes that have been proposed is presented. This review also presents a summarized discussion of the group multi-criteria methods that can be used to support the group decision of quickly identifying the more advanced and disadvantaged segments of countries in terms of their sustainable development. The third section describes the methodology proposed to assist decision-makers and the databases used to demonstrate its applicability. The fourth section demonstrates the applicability of the methodology by using the indicators available in the databases of the Sustainable Development Report 2019 (UN, 2019) and the Sustainability Society Index (SSI, 2016). Although only the indicators available in these two databases were used to exemplify the proposed methodology, the procedure represents a generic approach to cluster entities based on their sustainability status, be these entities, countries, cities or organizations. Finally, the last sections states conclusions, limitations and future work.

\section{Literature Review}

\subsection{Sustainability Indexes}

According to Mori and Christodoulou (2012) and Campagnolo, Carraro, Eboli, Farnia, Parrado, and Pierfederici (2018a) the conceptual requirements of a sustainability index are: 1) to consider the three key dimensions of sustainability: namely economic, social, and environmental; 2) to capture the external impact of SD beyond the city/region/country; 3) to define tangible indicators to assess the sustainability dimensions, and 4) to be applicable worldwide to enable comparisons and directions for improvement. However, developing a sustainability index or SD proxy is a difficult task due to the vagueness of the sustainability concept (Mensah, 
2019), the complexity of the issues to be covered by the metrics, and the diversity of disciplines underlying the concept (Wu \& Wu, 2012). As a result, a large variety of sustainability indexes and initiatives have been proposed (Cosbey, 2004). Among them, the 17 SDG established by the United Nations at the start of this millennium.

These SDGs are summarized as follows (Griggs et al., 2013; Sachs, 2012; Sachs \& McArthur, 2005): 1) prospering livelihood and improving quality of life through access to safe and sustainable water and sanitation, nutrition, health services, basic infrastructure, and education; 2) adoption of economic strategies based on sustainable practices such as the use of ecological technologies and energy systems; 3) achievement of long-term food security through sustainable systems of food production, distribution, and consumption; 4) efficient and secure water-resource management; 5) universal clean energy to mitigate global warming; 6) sustain biodiversity and ecosystems through evaluation, conservation, and restoration; 7) sustainable cities and communities; 8) governance for sustainable societies through the cooperation of governments and institutions at all levels by promoting global sustainable development and provide essential public goods and protection to citizens. Associated with these SDGs there are about 232 indicators. However, not all of them are available for each country at the required level of disaggregation (i.e., periodicity and geographic level), particularly for developing countries that are in general the less advanced in terms of attainment of SDG (Neumayer, 2001; Van de Kerk \& Manuel, 2008).

The SDGs represent a global benchmark, but other indexes, some focused on a particular pillar of sustainability, have been proposed. There is for example the Environmental Sustainability Index (ESI-2005) developed by Columbia and Yale Universities (Index, 2005) which contrasts the countries' capabilities to protect the environment for future generations. The ESI integrates 76 data sets into 21 latent indicators of environmental sustainability. These indicators correspond to the following five dimensions: Environmental systems, Environmental stresses, Human vulnerability to environmental stresses, Societal capacity to respond to environmental challenges, and Global stewardship. The Environmental Performance Index (EPI-2006), also developed through the joint cooperation of both universities (Esty et al., 2006), looks to improve the 'environmental dimension' of sustainability. EPI comprises 6 broad (latent) categories that have associated 16 indicators. Both indexes are mainly focused on the environmental dimension of sustainable development (Van de Kerk \& Manuel, 2008).

The Index for Sustainable Economic Welfare (ISEW) (Daly \& Cobb, 1989), as well as the Genuine Progress Indicator (GPI) (Cobb, Goodman, \& Wackernagel, 1999), are centered in the economic dimension of sustainability, and particularly in the improvement of the gross domestic product (GDP). While the Commitment to Development Index (CDI-2006) developed by the Center for Global Development and published yearly since 2003 by an independent not-for-profit organization in the USA (Stapleton \& Garrod, 2008) is mainly focused on human wellbeing. Specifically, the CDI reviews the level of support given by 21 countries to poor countries such that they may attain prosperity, good governance, and security. This composite index comprises indicators related to aid, investment, environment, security, and technology that are associated to six equally weighted dimensions.

Another outstanding set of sustainable development indicators is the Commission of Sustainable Development (CSD) Indicators which also resulted from a collaborative process between the Division for Sustainable Development (DSD) and the Statistics Division, both within the United Nations Secretariat (DESA, 2007). The initial set of 134 indicators comprising the CSD was voluntarily pilot-tested by 22 countries from 1996 to 1999 . Most of participant countries conclude the number of indicators was too large. Consequently, a reduction to 58 indicators covering policy-oriented themes was presented in 2001. The CSD indicators provide a relevant framework for the discussion of how to achieve the SDG based on national indicators. The overlap between the set of indictors comprising the CSD and MDG has created some confusion among policy-makers and professionals. However, their general purpose is different: the CSD indicators only provide a reference to track the progress toward national goals related to SD while the MDGs are focused on monitoring the progress toward the achievement of global goals. Additionally, the CSD covers a broader range of issues to cover the three main dimensions of sustainable development. Meanwhile the MDGs have a more limited coverage biased towards human welfare.

The Sustainable Society Index (SSI) has proposed a simplified index that integrates the three main dimensions of sustainability in a simple and transparent way. The SSI comprises only 22 indicators, grouped into 5 categories and is based on the definition of sustainable development of the Brundtland Commission. The SSI has been published and refined since 2006 and gives an appropriate insight about the sustainability level of 150 countries (Van de Kerk \& Manuel, 2008). This index represents an effort to capture the broad concept of sustainability 
with a manageable number of indicators grouped into seven sub-dimensions that represent a further decomposition of the three main dimensions of sustainability. Although the SSI and other existing indexes do not provide a completely valid measure of SD, the SSI represents a simple and quick proxy of sustainability.

\subsection{Group Multi-Criteria Decision-Making Methods}

Multi-Criteria Decision Methods (MCDM) can provide the support required for the multidisciplinary management of decisions such as the ones representatives of pro-sustainability organizations face when deciding what countries to support and how. There is an extensive variety of MCDM methods that can be used, among the most popular are: ELimination Et Choix Traduisant la REalitè (ELECTRE), Multi-attribute utility theory (MAUT), Analytical Hierarchy Process (AHP) and its variants, Fuzzy Analytical Hierarchy Process (FAHP) and Analytic Network Process (ANP), Technique for Order of Preference by Similarity to Ideal Solution (TOPSIS), and Preference Ranking Organization Method for Enrichment Evaluations (PROMETHEE). No method can be considered the ideal for every decision problem but the use of an unsuitable method can represent a potential risk. Therefore, when selecting a MCDM, it is necessary to carefully analyze the decision context and match the settings with the qualities and disadvantages of available methods (Wątróbski et al., 2019). According to Guarini, Battisti, and Chiovitti (2018), this requires the identification of exogenous and endogenous variables related to the decision-making problem. Exogenous variables are determined by the decision context while endogenous variables are defined after the analysis of the MCDM literature.

Any MCDM is generally structured in two macro-phases according to Guarini et al. (2018). But we extended this process to the following three macro-phases:

1) Identification of the different alternatives and their evaluation (performance) based on a set of criteria and sub-criteria. This phase results in the specification of an evaluation matrix.

2) Processing of the entries of the evaluation matrix to rate (describe), sort, rank, or select alternatives. The procedure to follow and their results depend on the method being used, and may vary from a simple linear combination of criteria (i.e., a compensatory approach) to a complex knowledge-driven approach that consider tradeoffs between criteria (i.e., outlining the Pareto frontier) or the attainment of ideal solutions, and

3) Aggregation of the judgments of DMs in the case of group decision-making problems. Group decision-making is a common method when the desired decision needs to fulfill the expectations of different stakeholders or the solution affects the interests of the participant DMs.

For several decision contexts (e.g., characterization of marketing segments, selection of research projects for financial support, ranking of suppliers according to their performance) important exogenous variables are recognized. For the decision problem of selecting what countries with similar sustainability problems require most attention, two exogenous variables at the first macro-phase were identified: the operationalization of a set of criteria that may be highly complex and imprecise, and the large dimensionality of the decision space, i.e., the size of the evaluation matrix. In the second macro-phase, the exogenous variables identified are: the expected solution and the technical support. Finally, in the third-macro phase, meaningful exogenous variables are: the diversity in the preferences, experiences, and backgrounds of DM, and the vagueness of their judgments regarding the relative importance of one criterion over another.

The first exogenous variable, the expected solution, is stated as "identifying the target segments that require particular attention" either because their sustainability strategy is outstanding or because they are worst ranked in SD. Regarding the second exogenous variable (size of the evaluation matrix), the main problem is the availability of reliable data for all world countries. This justifies the construction of a sustainability index based on a selected set of commonly available indicators. At the second macro-phase, we recognized the technical support available to support decision making may be low. Thus, easy to apply multi-criteria methods that can be implemented with the support of basic tools are preferred, particularly in the case of developing countries. Additionally, if the number of evaluation criteria is too large (over five) the number of pairwise comparisons required by some well-known multi-criteria methods (e.g., AHP and its extensions) results excessive for practical purposes and frequently results into inconsistencies

\section{Methodology}

The classification MCDM framework proposed by Wątróbski et al. (2019) according to their appropriateness to solve different decision-making problems and the practical guidelines offered by Guarini, Battisti, and Chiovitti (2018) allowed the identification of the following difficulties associated to the group multi-criteria decision-making (GMCDM): 1) the multi-dimensionality and latent nature of sustainability requires of a simplified index to be used as a proxy; 2 ) the large number of alternatives to evaluate (195 countries in the world) 
and the type of decision solution, acknowledged as sorting the countries into homogenous groups based on a sustainability score; and 3) the preferences of DMs regarding what sustainability aspects require more attention may involve some degree of vagueness and be considerably heterogeneous.

To address these difficulties, we propose the use of a summarized global SD score/index to rate countries, cluster them and rank the clusters to identify the segment(s) that lack behind in akin sustainability dimensions. The reduction of the dimensionality by transforming the multi-criteria problem into a single criterion requires of a weight vector, which is computed from the matrix of pairwise comparisons performed by the DMs. But, because of the potential low technical support available and the need of a prompt evaluation, an abbreviated procedure that facilitates the comparison process is required. Additionally, DM judgments involve some degree of vagueness or fuzziness, thus the use of fuzzy multi-criteria methods turns out to be convenient. Finally, as DMs represent the interests of different stakeholders (e.g., industrial, pro-environmental, and human rights organizations) and they comprise an interdisciplinary group, the aggregation of their individual weight vectors suggests the use of methods that take into account the heterogeneity of the individual priorities.

The methodology proposed to achieve the desired decision solution is described in Figure 1. The methodology is based on well-known quantitative methods, relatively easy to understand by practitioners, and to implement with the support of basic applications (e.g., Excel) or free software (e.g., R). Figure 1 describes the specific methods judged suitable to use at each phase of the decision-making process. When more than one technique is considered appropriate, a comparison of alternative methods was performed to suggest an ultimate procedure.

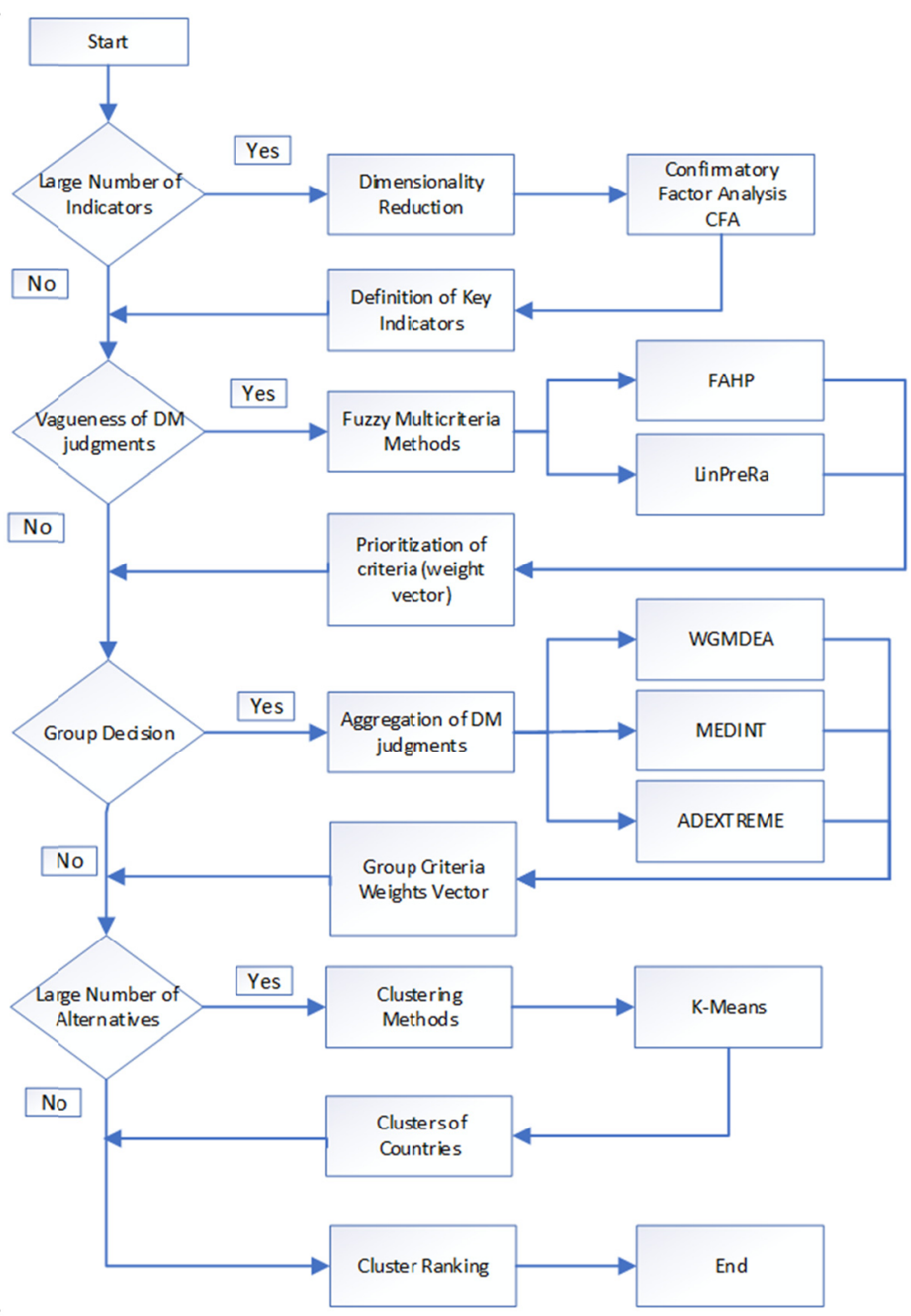

Figure 1. Flow chart describing the steps of the proposed methodology 
First, the application of two-level confirmatory factor analysis (CFA) is first proposed to solve the problem of reducing the number of indicators to use in the construction of a SD index. CFA results convenient not only to reduce the number of indicators but also to identifying and assigning key indicators to each latent dimension of sustainability. Secondly, fuzzy analytic hierarchy process (FAHP) (Chang, 1996) and fuzzy linguistic preference relations (Fuzzy LinPreRa) (Chen, Wang, \& Wu, 2011) methods are compared as alternative techniques for determining the level of importance (weights) that the DMs assign to all latent dimensions. Both methods are based on the principles of AHP, a well-grounded "theory of relative measurement that provides the analytical tool to model the complexity of the problem and process the subjective and personal judgment of individuals or a group in decision making" (Tan, Aviso, Huelgas, \& Promentilla, 2014, pp. 467-475). FAHP aggregates the DM's judgments to compute global priorities or weights to evaluate the alternatives and can handle the fuzziness of the DMs opinions.

Thirdly, to aggregate the individual judgments of DMs into a consensual weight vector (Grošelj, Malovrh, \& Stirn, 2011; Grošelj, Stirn, Danev, \& Krajčič, 2013) we compared the weighted geometric mean and data envelopment analysis (WGMDEA), the method of aggregation using interval judgments (MEDINT) and the adopted extreme values (ADEXTREME) against the commonly used Weighted Geometric Mean Method (WGMM) (Forman \& Peniwati, 1998). In a fourth stage, the K-means clustering algorithm was applied to group alternatives. K-means is a simple but efficient mathematical procedure that helps to reduce the number of alternatives on which DMs should focus (Kodinariya \& Makwana, 2013). Finally, clusters are ranked according to the group priorities to identify and characterize the "best" and "worst" clusters in terms of the achievement of sustainable goals.

The proposed methodology is applied to the problem of identifying critical indicators to measure the sustainable development of worldwide countries and identify groups of disadvantaged countries. The input data comes from two secondary data sources: the UN sustainable development report 2019 (UN, 2019) and the indicators of the sustainable society index (SSI) (http://www.ssfindex.com/). Other interrelated indicators of sustainability can be also used to improve the reliability and validity of the SD index. However, because the main purpose of this work is to demonstrate the applicability of the methodology outlined in Figure 1, we only used the indicators of the UN and SSI databases.

\section{Results}

According to the methodology, the first step is the reduction of the number of sustainable indicators, acknowledged as criteria in the context of multi-criteria methods, to a manageable but still meaningful set. To complete this reduction, it is necessary to define the dimensions and sub-dimensions of the latent concept. This step was performed based on the extant literature, mainly on the SDG indexes set by the UN and the SSI. The proposed structure of the sustainability construct described in Figure 2 takes as reference the SSI framework (http://www.ssfindex.com/ssi/framework/).

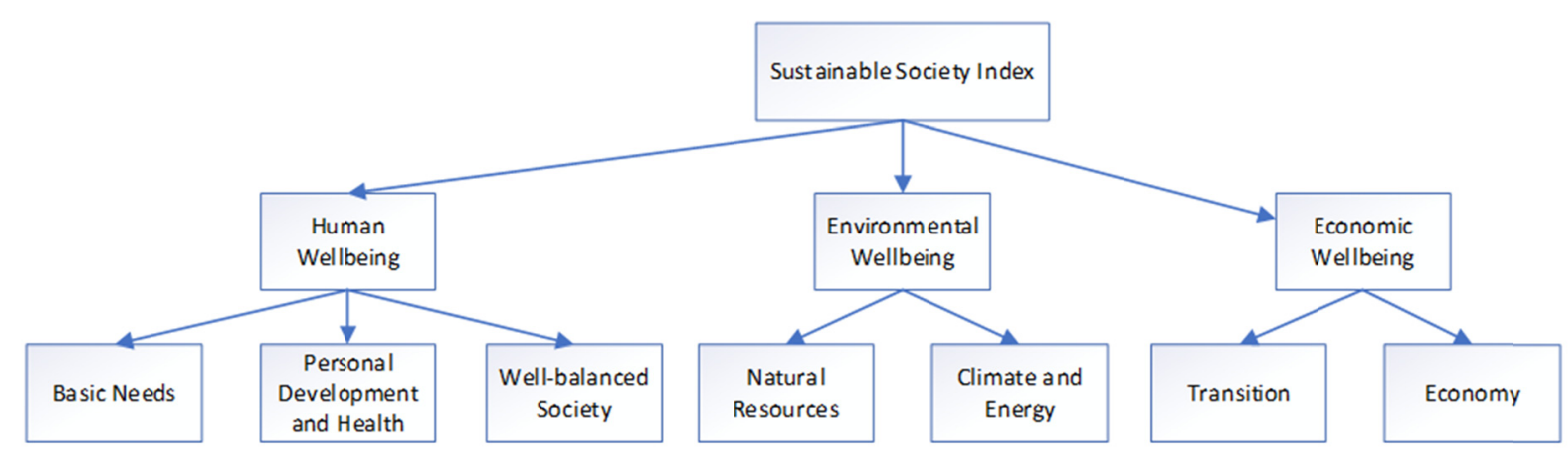

Figure 2. Structure of the sustainability construct, based on SSI framework (2019)

According to Figure 2, sustainability comprises three main or first-order dimensions: human wellbeing, environmental wellbeing, and economic wellbeing. Each of these dimensions are also latent variables with several dimensions (sub-dimensions). Then, the 114 indicators proposed by the $\mathrm{UN}$ and the 21 indicators proposed by the SSI were associated with each sustainability sub-dimensions. Because complete information of all these indicators was not available for all countries, only 52 indicators were used. 
Following the methodology, a two-level confirmatory factor analysis (CFA) was performed. The estimation of the coefficients of the proposed two-dimensional structure of sustainability was performed by using the Partial Least Squares (PLS) method which is a distribution-free method. The model parameters are estimated by maximizing the variance explained for all endogenous constructs by means of a series of ordinary least squares regressions (Reinartz, Haenlein, \& Henseler, 2009). PLS does not require large sample sizes because it uses bootstrapping to estimate the standard errors of the coefficients to perform hypothesis testing (Sharma \& Kim, 2013) instead of assuming a sampling distribution to compute the standard errors of the coefficient estimators (Hair, Ringle, \& Sarstedt, 2011). Thus, PLS is recommended to fit the measurement model of Figure 2.

CFA confirms the indicators proposed are indeed related to the lower order latent variables (sub-dimensions in the terminology of two-order confirmatory factor analysis and sub-criteria according to AHP) to which were assigned. Goodness-of-fit measures indicated a fair fit of the measurement model according to the literature recommendations (Hair et al., 2011; Hooper, Coughlan, \& Mullen, 2008). The goodness-of-fit Index (GFI = .882) and the adjusted GFI (AGFI) were slightly below the recommended bound of 0.9 (AGF1 $=.890)$ while the Root Mean Square Error was below the recommended limit of 0.5 (RMSE $=.009)$.

CFA also allows discarding non-critical indicators based on the loadings or correlations of each indicator with its corresponding latent variable (Muthén, 2001a; Muthén, 2001b). The final measurement model is shown in Figure 3. Only 28 indicators were selected, thus a significant reduction in the number of indicators required to compute a global sustainability index was obtained. According to Figure 3, specific indicators are associated with the sub-dimensions while the scores of the lower-order model act as observed variables for the higher-order dimensions. Thus, the application of CFA combines the use of quantitative tangible indicators with non-observable or latent variables through the establishment of "causal" relations confirmed by the estimation of the model (Punniyamoorthy, Mathiyalagan, \& Parthiban, 2011).

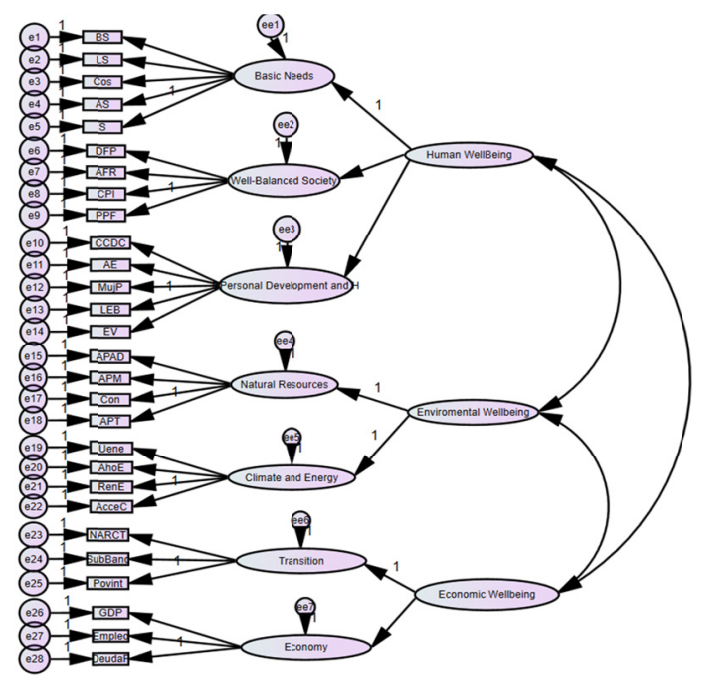

Figure 3. Two-level confirmatory factor analysis (CFA) model

In the second step of the methodology, a group of decision-makers (DM) is formed. In this work, a group of six DMs with different viewpoints was simulated. In a real situation, sustainability experts, policy-makers and representatives of global organizations will be selected to integrate the decision group. To obtain individual crisp judgments about the relative importance of each criterion, each of the DM needs to perform multiple pairwise comparisons. These individual comparisons are finally summarized in a priority vector that expresses the relative importance that a particular DM assigns to each of the sub-dimensions and dimensions of sustainability (Saaty \& Vargas, 2006).

Following the methodology, triangular fuzzy numbers (TFN) are assigned to the linguistic pairwise comparisons performed by the DMs. To reduce the complexity to obtaining weights from the TFN (Tan et al., 2014, pp. 467-475), the use of two methods was proposed: a) the modified Extent Analysis Method (EAM) of fuzzy AHP proposed by Ahmed and Kilic (2015) to amend some drawbacks of the EAM initially proposed by Chang (1992); and b) Fuzzy LinPreRa (Chen et al., 2011). This last method reduces the number of pairwise comparisons 
required to only n-1 while FAHP requires n(n-1)/2 pairwise comparisons (Chen et al., 2011) which may become excessive when the number of criteria (n) is too large. Additionally, Fuzzy LinPreRa assures consistency of judgments and it is more convenient to acquire the judgments of DMs through a questionnaire online. Thus, the method is a simpler and convenient alternative to EAM-FAHP (Herrera-Viedma, Herrera, Chiclana, \& Luque, 2004). We compared the two approaches to support the recommendation of using Fuzzy LinPreRa instead of extent FAHP.

The linguistic scale described in Table 1 and its corresponding triangular fuzzy numbers (L, M, U) was used to record the opinions of each of the DMs for both methods, EAM and Fuzzy LinPreRa.

Table 1. Fuzzy linguistic scale

\begin{tabular}{lll}
\hline Linguistic Scale & Triangular Fuzzy Number & Triangular Fuzzy reciprocal scale \\
\hline Demonstrated Importance & $(7,9,11)$ & $(1 / 11,1 / 9,1 / 7)$ \\
Very Strong Importance & $(5,7,9)$ & $(1 / 9,1 / 7,1 / 5)$ \\
Strong Importance & $(3,5,7)$ & $(1 / 7,1 / 5,1 / 3)$ \\
Moderate Importance & $(1,3,5)$ & $(1 / 5,1 / 3,1)$ \\
Equal Importance & $(1,1,1)$ & $(1,1,1)$ \\
\hline
\end{tabular}

Note. Adapted from Ballı and Korukoğlu, 2009.

Details of FAHP methodology are provided for example in (Chen et al., 2011; Kabir \& Hasin, 2011). The main steps of the methodology are summarized as follows:

a. Each of the DM expresses his/her judgments after making linguistic pairwise comparisons between $\mathrm{n}$ dimensions at the same level of the hierarchy. For example, there are three dimensions at the first level of the hierarchy depicted in Figure 2, they are human wellbeing (HW), environmental wellbeing (EW), and economic wellbeing $(\mathrm{EcW})$. Then each DM needs to make 3(3-1)/2 $=3$ pairwise comparisons.

b. The linguistic pairwise comparisons are transformed into TFN according to Table 1. For example, the linguistic judgment of DM1 when comparing dimension 1 (HW) versus dimension 2 (EW) is "very strong importance", then to entry $\mathrm{A}_{(1,2)}$ of the individual decision matrix $\mathrm{A}_{1}$ corresponds to the TFNs $(5$, 7, 9). Using this assignment scheme, the entries of the upper triangular part of the matrix $A$ are found. The lower triangular part of matrix A is simply computed by the reciprocals of the TFN. For example, $\mathrm{A}_{(1,2)}=(5,7,9)$ while $\mathrm{A}_{(2,1)}=(1 / 9,1 / 7,1 / 5)$.

c. The modified EAM (Chang, 1992; Kabir \& Hasin, 2011) is then applied to obtain synthetic extent values corresponding to the relative weights or priorities assigned to the criteria by each of the DM.

The alternative approach to compute crispy weights is Fuzzy LinPreRa (Chen et al., 2011). The main steps of this methodology are summarized as follows:

a. Each of the DM expresses his/her judgments through only (n-1) linguistic pairwise comparisons between $n$ dimensions at the same level of the hierarchy. For example, at the second level of the hierarchy there are $\mathrm{n}=7$ sub-dimensions. Then only six comparisons are required, while FAHP requires $7(6) / 2=21$ comparisons. Thus, LinPreRa method considerably reduces the number of required pairwise comparisons.

b. The linguistic pairwise comparisons are transformed into TFN. Following the procedure described in (Chen et al., 2011), a transformation function $g\left(a_{\mathrm{ij}}\right)=1 / 2 \cdot\left(1+\log _{11} \mathrm{a}_{\mathrm{ij}}\right)$ is used to compute the entries of the A matrix. For example, the $\mathrm{A}_{(1,2)}$ entry of the individual matrix $\mathrm{A}_{1}$ (associated with DM1) after applying the transformation function becomes $(0.84,0.91,0.96)$.

c. To estimate the missing pairwise comparisons, proposition 2.3 .2 stated by Chen et al. (2011, p. 1325) to assure a consistent reciprocal fuzzy linguistic preference relation is used. For example for DM1, A $(2,1)$ is computed by using $\mathrm{p}_{(2,1)}^{\mathrm{L}}=1-\mathrm{p}_{(1,2)}^{\mathrm{R}}, \mathrm{p}_{(2,1)}^{\mathrm{M}}=1-\mathrm{p}_{(1,2)}^{\mathrm{M}}$, and $\mathrm{p}_{(2,1)}^{\mathrm{R}}=1-\mathrm{p}_{(1,2)}^{\mathrm{L}}$, to get $\mathrm{A}_{(2,1)}=(0.04,0.09$, $0.16)$.

d. The transformation function $\mathrm{f}\left(\mathrm{x}^{\mathrm{K}}\right)=\left(\mathrm{X}^{\mathrm{K}}+\mathrm{c}\right) /(1+2 \mathrm{c})(\mathrm{K}=\mathrm{L}, \mathrm{M}, \mathrm{U})$ is used to prevent negative fuzzy numbers while preserving reciprocity and additive consistency.

e. Finally, a defuzzification method is used to compute the individual weight vectors. Common methods for defuzzification are the mean of maximal (MOM), center of area (COA), and $\alpha$-cut methods. We applied the COA method because it is simple and practical (Talon \& Curt, 2017) thus resolving the 
difficulty of limited technical support.

The weight vector of DM1, computed with the extent analysis method of Fuzzy AHP and Fuzzy LinPreRa are shown in Table 2. An overall good correspondence between the weights or priorities computed with each method is observed for all sustainability sub-dimensions (the geometric mean equals $8 \%$ and the median is $8.5 \%$ ). Two largest percentage difference $(45.00 \%)$ is the priority assigned to the Human Wellbeing sub-dimensions of a well-balanced society. Regarding the main dimensions, the weights assigned to Economic Wellbeing registered the largest discrepancy. These differences may be explained by the forced consistency implicit in the Fuzzy LinPreRa method. But because Fuzzy LinPreRa reduces the number of pairwise comparisons and prevents inconsistencies, its application is recommended to facilitate the comparison process and computations.

Table 2. Comparisons between DM1 FAHP and Fuzzy LinPreRa dimensions weights sets

\begin{tabular}{llll}
\hline Environmental Dimensions & FAHP & LinPreRa & Percentage Difference \\
\hline Human Wellbeing & 0.42 & 0.47 & $11.90 \%$ \\
Environmental Wellbeing & 0.29 & 0.30 & $3.45 \%$ \\
Economic Wellbeing & 0.29 & 0.23 & $26.09 \%$ \\
Basic Needs & 0.38 & 0.48 & $26.32 \%$ \\
Personal Development and Health & 0.29 & 0.32 & $10.34 \%$ \\
Well Balanced Society & $\mathbf{0 . 2 9}$ & $\mathbf{0 . 2 0}$ & $45.00 \%$ \\
Natural Resources & 0.70 & 0.68 & $2.94 \%$ \\
Climate and Energy & 0.30 & 0.32 & $6.67 \%$ \\
Transition & 0.42 & 0.43 & $2.38 \%$ \\
Economy & 0.58 & 0.57 & $1.75 \%$ \\
\hline
\end{tabular}

Note. The percentage difference is computed as follows: $\%$ difference $=[(\max / \min )-1] * 100$ 。

The next step of the methodology is the aggregation of the individual weight vectors to get a group weight vector. When priorities are similar, namely there is consensus among the DMs regarding the importance of each dimension, the usual procedure is to average the weights by using the geometric mean (Forman \& Peniwati, 1998). However, when individual priorities are heterogeneous, other methods have been proposed. In this work, we applied the following aggregation methods: Weighted Geometric Data Envelopment Analysis method (WGMDEA), MEDINT method and Adopted extreme values method (ADEXTREME). The first method, WGMDEA is a hybrid method that combines the weighted geometric mean method (WGMM) with data envelopment analysis method (DEA) (Wang \& Chin, 2009). The Median Interval (MEDINT) method (Grošelj et al., 2011) and the Adopted Extreme Values (ADEXTREME) method applied a different computational approach based on the use of interval comparison matrices. MEDINT uses values below and above the median for constructing the lower and upper bounds of the interval while ADEXTREME aggregates individual judgments into a group interval that reflects all individual judgments but the minimum and maximum values have the highest influence.

Table 3 summarizes the results obtained by applying the three aggregation methods. WGMDEA is not compared with the other two methods because it is based on a linear programming (LP) approach while the other methods use a different rationale but they are simpler and thus attractive for practical purposes.

Table 3. Group weight vectors for sustainability sub-dimensions computed with different aggregation methods

\begin{tabular}{|c|c|c|c|c|c|c|}
\hline & \multicolumn{2}{|c|}{ WGMDEA } & \multirow[b]{2}{*}{$\begin{array}{l}\text { Percentage } \\
\text { Difference }\end{array}$} & \multirow[b]{2}{*}{ MEDINT } & \multirow[b]{2}{*}{ ADEXTREME } & \multirow[b]{2}{*}{$\begin{array}{l}\text { Percentage } \\
\text { Difference }\end{array}$} \\
\hline & FAHP & $\begin{array}{l}\text { Fuzzy } \\
\text { LinPreRa }\end{array}$ & & & & \\
\hline \multicolumn{7}{|l|}{ Main dimensions of sustainability } \\
\hline Human Wellbeing & 0.40 & 0.39 & $2.56 \%$ & 0.56 & 0.56 & $0.00 \%$ \\
\hline Environmental Wellbeing & 0.31 & 0.31 & $0.00 \%$ & 0.33 & 0.33 & $0.00 \%$ \\
\hline Economic Wellbeing & 0.29 & 0.28 & $3.57 \%$ & 0.11 & 0.11 & $0.00 \%$ \\
\hline \multicolumn{7}{|l|}{ Sub-dimensions } \\
\hline Basic Needs & 0.39 & 0.35 & $11.43 \%$ & 0.55 & 0.55 & $0.00 \%$ \\
\hline Personal Development and Health & 0.32 & 0.29 & $10.34 \%$ & 0.29 & 0.33 & $13.79 \%$ \\
\hline Well Balanced Society & 0.30 & 0.28 & $7.14 \%$ & 0.16 & 0.12 & $33.33 \%$ \\
\hline Natural Resources & 0.62 & 0.57 & $8.77 \%$ & 0.56 & 0.65 & $16.07 \%$ \\
\hline Climate and Energy & 0.38 & 0.44 & $15.79 \%$ & 0.44 & 0.35 & $25.71 \%$ \\
\hline Economy & 0.64 & 0.63 & $1.59 \%$ & 0.75 & 0.75 & $0.00 \%$ \\
\hline Transition & 0.36 & 0.37 & $2.78 \%$ & 0.25 & 0.25 & $0.00 \%$ \\
\hline
\end{tabular}

Note. The percentage difference is computed as follows: $\%$ difference $=[(\max / \min )-1] * 100$. 
The comparison of the three aggregation methods shows the ranking of importance of the three main dimensions and seven sub-dimensions comprising the sustainability concept is preserved. The group of DMs assign the highest priority to Human Wellbeing, this result agrees with the MDG. Regarding the sub-dimensions' priorities, satisfying the basic needs of the world population (access to education, nutrition, sanitation, etc.) are the most important component of Human Wellbeing. Meanwhile preserving natural resources and biodiversity has the highest priority among the sub-dimensions of Environmental Wellbeing. For the last sustainability dimension, Economic Wellbeing, keeping a steady economic growth was judged the most relevant component.

Minor percentage differences occur when WGMDEA is used to aggregate the individual weight vectors computed by using EAM-FAHP and Fuzzy LinPreRa (discarding the cases where weights are equal, the geometric mean of the percentage differences equals 5.52\%). Differences between MEDINT and ADEXTREME methods are observed in the case of sub-dimensions. Again, discarding the cases where weights are equal, the geometric mean of the percentage difference is $20.88 \%$. Because the difference among the tree aggregation methods is below $30 \%$ (a bound considered in statistics as low variability), any one could be a reasonable choice. However, the final recommendation is to use the WGMDEA method because the other two methods only offer possibilities that some alternatives are better than others, therefore they are expected to be more imprecise.

The next step of the methodology is to segment the 154 countries into clusters with similar sustainability indicators. K-Means is a simple unsupervised machine learning algorithm that requires basic technical support to be implemented. This method has been extensively used in several areas with satisfactory empirical results (Jain, 2010). The rationale of the algorithm is to find a partition of the alternatives such that the variability between the cluster's centroids (vector of sub-dimensions' averages) (SSB) is maximized while the variability within the cluster is minimized (SSE). If each alternative is assigned to a cluster ( $\mathrm{k}=\mathrm{m}$ countries), then $\mathrm{SSE}=0$, thus the goal is to identify a small value of $k$ that still provides a low SSE.

To define the number of clusters we applied the elbow method which consists of plotting the number of clusters against the sum of squares of error (SSE) and identify the point $k$ where SSE stabilizes or does not decrease substantially (Syakur, Khotimah, Rochman, \& Satoto, 2018). The application of this method resulted in a partition of the alternatives (countries) into $\mathrm{k}=10$ clusters, a solution which was judged appropriate because groups are homogeneous and well separated. Table 4 shows the centroids of each cluster.

The cluster centroids represent the (Euclidean) distance to the associated sustainability goal which ideal value is 1. The larger the distance, the smaller the progress of the segment in achieving the SDG for which the sub-dimension serves as proxy. Authors such as Stapleton and Garrod (2008) have shown there is little justification for relaxing the equal weights assumption in the specific case of the commitment to development index (CDI). Taking his approach, then the global sustainability development score of each cluster is simply the sum of the sub-dimension's scores that is Ggs $=\sum \mathrm{SDi}$. According to this index, the most advanced cluster of countries is $\mathrm{C} 10$ with a score of 2.80 (the smallest average distance with respect to the ideal of 1.0) and the least advanced cluster is $\mathrm{C} 8$ with a global SD score of 4.79 .

Table 4. Clusters centroids

\begin{tabular}{lllllllllll}
\hline Sustainability sub-dimensions & C1 & C2 & C3 & C4 & C5 & C6 & C7 & C8 & C9 & C10 \\
\hline Basic Needs & 0.59 & 0.34 & 0.07 & 0.68 & 0.55 & 0.04 & 0.09 & 0.20 & 0.33 & 0.37 \\
Personal Development and Health & 0.54 & 0.53 & 0.78 & 0.48 & 0.60 & 0.91 & 0.41 & 0.71 & 0.59 & 0.14 \\
Well Balanced Society & 0.53 & 0.64 & 0.58 & 0.27 & 0.65 & 0.56 & 0.52 & 0.59 & 0.52 & 0.47 \\
Natural Resources & 0.20 & 0.25 & 0.81 & 0.44 & 0.36 & 0.36 & 0.35 & 0.79 & 0.53 & 0.19 \\
Climate and Energy & 0.28 & 0.63 & 0.89 & 0.28 & 0.31 & 0.69 & 0.70 & 0.71 & 0.43 & 0.36 \\
Economy & 0.25 & 0.38 & 0.69 & 0.09 & 0.16 & 0.85 & 0.74 & 0.62 & 0.39 & 0.20 \\
Transition & 0.72 & 0.50 & 0.25 & 0.54 & 0.51 & 0.48 & 0.35 & 0.58 & 0.61 & 0.48 \\
\hline
\end{tabular}

Figure 4 provides a graphical representation of the clusters in the space of the three main dimensions of sustainability, namely Human Wellbeing, Environmental Wellbeing, and Economic Wellbeing. The stars, which are visually well separated, are the clusters' centroids while the dots are the countries evaluated. In Figure 4, it can also be appreciated that, as expected, the maximum Euclidian distance between clusters corresponds to the "extreme" clusters, i.e., C10-C8. However, according to Table 3, there are important differences in the priorities the group of DMs assigned to the SD sub-dimensions and consequently to the main dimensions of sustainability. Therefore, a weighted global score that takes into consideration the judgments of the group of DMs regarding what sustainability aspects require more attention is finally proposed as the last step of the methodology (see 
Figure 1).

Clusters are ranked by using a "utility" weighted score computed as $\mathrm{EV}_{\mathrm{k}}=\sum\left(1-\mathrm{SD}_{\mathrm{i}}\right)\left(\mathrm{w}_{\mathrm{i}}\right)$, where $\mathrm{w}_{\mathrm{i}}$ is the group weight or priority assigned to the $\mathrm{i}$-th subdimension, $\mathrm{i}=1,2, \ldots, 7$ sub-dimensions and $\mathrm{k}=1,2, \ldots, 10$ clusters. Notice we subtracted the SD index from " 1 ", such that the resulting overall score can be interpreted as the utility resulting from a superior fulfillment of the sustainability goals. Consequently, lower scores represent the "disutility" that results from the poor performance of the strategies defined to attain the sustainability goals.

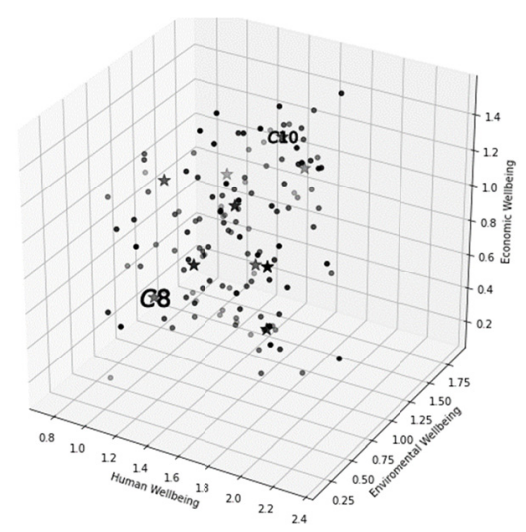

Figure 4. Graphical representation of clusters

Table 5 reports the utility scores of the ten clusters computed using the group weights obtained with each of the four aggregation methods. It is important to notice that the four scores identified the same extreme cases: the clusters categorized as the "worst" (C8) and "best" (C10) in terms of sustainable development. However, this coincidence cannot be generalized to other applications. Therefore, as previously established, the recommendation to generate a full hierarchy of clusters is to use the group weights computed with WGMDEA.

Table 5. Cluster utility calculation of different aggregation methods

\begin{tabular}{lllll}
\hline & \multicolumn{2}{l}{ WGMDEA } & & \\
\cline { 2 - 3 } Cluster & FAHP & Fuzzy LinPreRa & MEDINT & ADEXTREME \\
\hline C1 & 0.59 & 0.56 & 0.56 & 0.57 \\
C2 & 0.56 & 0.53 & 0.57 & 0.58 \\
C3 & 0.41 & 0.38 & 0.46 & 0.46 \\
C4 & 0.61 & 0.59 & 0.54 & 0.53 \\
C5 & 0.57 & 0.55 & 0.54 & 0.54 \\
C6 & 0.45 & 0.43 & 0.54 & 0.54 \\
C7 & 0.55 & 0.51 & 0.62 & 0.64 \\
C8 & $\mathbf{0 . 4 0}$ & $\mathbf{0 . 3 8}$ & $\mathbf{0 . 4 5}$ & $\mathbf{0 . 4 5}$ \\
C9 & 0.53 & 0.50 & 0.55 & 0.54 \\
C10 & $\mathbf{0 . 7 1}$ & $\mathbf{0 . 6 7}$ & $\mathbf{0 . 7 0}$ & $\mathbf{0 . 7 2}$ \\
\hline
\end{tabular}

The cluster with the highest SD utility (C10) includes countries ranked high according to the Global Index Score (Sachs, Schmidt-Traub, Kroll, Lafortune, \& Fuller, 2018): Austria (9), Belgium (12), Germany (4), Estonia (10), Finland (3), Japan (15), Norway (6) and Sweden (1). Although these countries are characterized by their efforts to preserve their natural resources, their economic development, and the quality of life of their inhabitants (Kalimeris, Bithas, Richardson, \& Nijkamp, 2020), they are not the first nine of the ranking. This discrepancy is due to the structure of the sustainability indexes used to rank the countries. The SD index developed in this work is a simplified and unified version of the NU and SSI indexes. However, the resultant sustainability index offers the advantages of simplicity and low data requirements, while still providing a practical and prompt way to roughly assess the sustainability status of world countries.

In contrast, the most disadvantaged cluster (C8) includes countries such as Burundi, Haiti, Libya, Papua New Guinea, and Sudan where Human Welfare (the dimension with the highest priority) has not been achieved because of a depressed economy, debt distress, and low industrialization. These countries also have faced 
environmental disasters and civil wars that affect their performance in other sustainability dimensions. More specifically, some of these countries (e.g., Haiti and Sudan) are characterized by chronic widespread poverty and food insecurity that prevents fulfilling the basic needs of the population (access to education, public health, etc.) which is the most important sub-dimension of Human Welfare (Berridge, 2020; Gibson, 2020; Hendriks, Reis, Sostakova, \& Berckmoes, 2020; Kwan et al., 2020; Swesi, El-Anis, \& Islam, 2020).

\section{Conclusions}

The methodology proposed in this study offers a practical approach to assess the sustainability of different entities to design strategies and assign resources to advance sustainable development. The use of well-known and relatively easy to implement quantitative methodologies allows the reduction in the number of indicators required to operationalize the sustainability concept; enables the computation of group weight vectors associated to each of the dimensions and sub-dimensions comprising sustainability; identifies segments of countries with similar degrees of advance in the set of sustainability proxies, and ranks the segments to identify extreme groups.

The comparison of different approaches to obtain individual crispy priorities for the sustainability dimensions and aggregate the ambiguous judgments of DMs with different perspectives and backgrounds, indicates Fuzzy LinPreRa and WGMDEA are suitable methods that offer practical and computational advantages. Finally, the segmentation of countries reduces the number of alternatives to evaluate and simplifies the identification of countries that face similar challenges and thus can follow the same sustainability path.

The main limitations of this study are: a) the proposed methodology was demonstrated only for the specific case of assessing the advance of the world's countries in the attainment of the sustainability goals established by the United Nations, and b) the SD index is based only on the indicators associated to the SDG and SSI indexes. Therefore, extensions to this work include the use of additional indicators to improve the content validity of the SD index and application of the methodology to other cases where the sustainability of different entities need to be assessed as part of a GMCDM problem where the desired solution is the generation of ordered clusters, which considers the preference degree between sustainable aspects.

\section{References}

Ahmed, F., \& Kilic, K. (2015). Modification to fuzzy extent analysis method and its performance analysis (pp. 435-438). In 2015 International Conference on Industrial Engineering and Systems Management (IESM). IEEE. https://doi.org/10.1109/IESM.2015.7380193

Ballı, S., \& Korukoğlu, S. (2009). Operating system selection using fuzzy AHP and TOPSIS methods. Mathematical and Computational Applications, 14(2), 119-130. https://doi.org/10.3390/mca14020119

Bauldry, S., Bollen, K. A., \& Adair, L. S. (2015). Evaluating measurement error in readings of blood pressure for adolescents and young adults. Blood Pressure, 24(2), 96-102. https://doi.org/10.3109/08037051.2014.986952

Berridge, W. (2020). Briefing: The Uprising in Sudan. African Affairs, 119(474), 164-176. https://doi.org/10.1093/afraf/adz015

Campagnolo, L., Carraro, C., Eboli, F., Farnia, L., Parrado, R., \& Pierfederici, R. (2018a). The ex-ante evaluation of achieving sustainable development goals. Social Indicators Research, 136(1), 73-116. https://doi.org/10.1007/s11205-017-1572-x

Campagnolo, L., Eboli, F., Farnia, L., \& Carraro, C. (2018b). Supporting the UN SDGs transition: Methodology for sustainability assessment and current worldwide ranking. Economics: The Open-Access, Open-Assessment E-Journal, 12(10), 1-19. https://doi.org/10.5018/economics-ejournal.ja.2018-10

Chang, D.-Y. (1992). Extent analysis and synthetic decision. Optimization Techniques and Applications, 1(1), $352-355$.

Chang, D.-Y. (1996). Applications of the extent analysis method on fuzzy AHP. European Journal of Operational Research, 95(3), 649-655. https://doi.org/10.1016/0377-2217(95)00300-2

Chen, Y.-H., Wang, T.-C., \& Wu, C.-Y. (2011). Multi-criteria decision making with fuzzy linguistic preference relations. Applied Mathematical Modelling, 35(3), 1322-1330. https://doi.org/10.1016/j.apm.2010.09.009

Cobb, C. W., Goodman, G. S., \& Wackernagel, M. (1999). Why bigger isn't better: the genuine progress indicator: 1999 Update (pp. 3-5). San Fransisco: Redefining Progress.

Cosbey, A. (2004). A Capabilities Approach to Trade and Sustainable Development: Using Sen's Conception of Development to Re-examine the Debates. A Capabilities Approach to Trade and Sustainable Development: 
Using Sen's Conception of Development to Re-Examine the Debates.

Daly, H., \& Cobb, J. B. Jr. (1989). For the Common Good. Redirecting the Economy Toward Community, the Environment and a Sustainable Future. Boston, Massachusetts: Beacon Press. https://doi.org/10.1177/027046769101100137

Desa, U. (2007). Indicators of Sustainable Development: Guidelines and Methodologies (p. 93). New York, USA: UN DESA.

Forman, E., \& Peniwati, K. (1998). Aggregating individual judgments and priorities with the analytic hierarchy process. European Journal of Operational Research, 108(1), 165-169. https://doi.org/10.1016/S0377-2217(97)00244-0

Gibson, J. (2020). Deforestation and Resource Conflicts in Papua New Guinea (No. 20/02).

Griggs, D., Stafford-Smith, M., Gaffney, O., Rockström, J., Öhman, M. C., Shyamsundar, P., ... Noble, I. (2013). Policy: Sustainable development goals for people and planet. Nature, 495(7441), 305. https://doi.org/10.1038/495305a

Grošelj, P., Malovrh, Š. P., \& Stirn, L. Z. (2011). Methods based on data envelopment analysis for deriving group priorities in analytic hierarchy process. Central European Journal of Operations Research, 19(3), 267-284. https://doi.org/10.1007/s10100-011-0191-x

Grošelj, P., Zadnik Stirn, L., Danev, G., \& Krajčič, D. (2013). Ranking strategic and operative goals for sustainable development of Pohorje, Slovenia. Acta silvae et ligni, 100, 47-55. https://doi.org/10.20315/ASetL.100.5

Guarini, M. R., Battisti, F., \& Chiovitti, A. (2018). A methodology for the selection of multi-criteria decision analysis methods in real estate and land management processes. Sustainability, 10(2), 507. https://doi.org/10.3390/su10020507

Hair, J. F., Ringle, C. M., \& Sarstedt, M. (2011). PLS-SEM: Indeed a silver bullet. Journal of Marketing Theory and Practice, 19(2), 139-152. https://doi.org/10.2753/MTP1069-6679190202

Hendriks, T. D., Reis, R., Sostakova, M., \& Berckmoes, L. H. (2020). Violence and Vulnerability: Children's Strategies and the Logic of Violence in Burundi. Children \& Society, 34(1), 31-45. https://doi.org/10.1111/chso.12349

Herrera-Viedma, E., Herrera, F., Chiclana, F., \& Luque, M. (2004). Some issues on consistency of fuzzy preference relations. European Journal of Operational Research, 154(1), 98-109. https://doi.org/10.1016/S0377-2217(02)00725-7

Hooper, D., Coughlan, J., \& Mullen, M. R. (2008). Structural equation modelling: Guidelines for determining model fit. Electronic Journal of Business Research Methods, 6(1), 53-60.

Index, E. S. (2005). Benchmarking national environmental stewardship. Yale Center for Environmental Law and Policy, Yale University.

Jain, A. K. (2010). Data clustering: 50 years beyond K-means. Pattern Recognition Letters, 31(8), 651-666. https://doi.org/10.1016/j.patrec.2009.09.011

Kabir, G., \& Hasin, M. A. A. (2011). Comparative analysis of AHP and fuzzy AHP models for multicriteria inventory classification. International Journal of Fuzzy Logic Systems, 1(1), 1-16.

Kalimeris, P., Bithas, K., Richardson, C., \& Nijkamp, P. (2020). Hidden linkages between resources and economy: A "Beyond-GDP" approach using alternative welfare indicators. Ecological Economics, 169, 106508. https://doi.org/10.1016/j.ecolecon.2019.106508

Keeble, B. R. (1988). The Brundtland report: 'Our common future'. Medicine and War, 4(1), 17-25. https://doi.org/10.1080/07488008808408783

Kodinariya, T. M., \& Makwana, P. R. (2013). Review on determining number of Cluster in K-Means Clustering. International Journal, 1(6), 90-95.

Kwan, G. F., Yan, L. D., Isaac, B. D., Bhangdia, K., Jean-Baptiste, W., Belony, D., ... Pierre-Louis, D. (2020). High Poverty and Hardship Financing Among Patients with Noncommunicable Diseases in Rural Haiti. Global Heart, 15(1). https://doi.org/10.5334/gh.388

Mensah, G. (2019). Financial Sustainability of Christian Aid Ghana. University of Ghana. 
Mori, K., \& Christodoulou, A. (2012). Review of sustainability indices and indicators: Towards a new City Sustainability Index (CSI). Environmental Impact Assessment Review, 32(1), 94-106. https://doi.org/10.1016/j.eiar.2011.06.001

Muthén, B. O. (2001a). Second-generation structural equation modeling with a combination of categorical and continuous latent variables: New opportunities for latent class-latent growth modeling. American Psychological Association. https://doi.org/10.1037/10409-010

Muthén, B. O. (2001b). Latent variable mixture modeling. In New developments and techniques in structural equation modeling (pp. 21-54). Psychology Press.

Neumayer, E. (2001). The human development index and sustainability-A constructive proposal. Ecological Economics, 39(1), 101-114. https://doi.org/10.1016/S0921-8009(01)00201-4

Punniyamoorthy, M., Mathiyalagan, P., \& Parthiban, P. (2011). A strategic model using structural equation modeling and fuzzy logic in supplier selection. Expert Systems with Applications, 38(1), 458-474. https://doi.org/10.1016/j.eswa.2010.06.086

Reinartz, W., Haenlein, M., \& Henseler, J. (2009). An empirical comparison of the efficacy of covariance-based and variance-based SEM. International Journal of Research in Marketing, 26(4), 332-344. https://doi.org/10.1016/j.ijresmar.2009.08.001

Saaty, T. L., \& Vargas, L. G. (2006). Decision making with the analytic network process (Vol. 282). Springer Science + Business Media, LLC.

Sachs, J. D. (2012). From millennium development goals to sustainable development goals. The Lancet, 379(9832), 2206-2211. https://doi.org/10.1016/S0140-6736(12)60685-0

Sachs, J. D., \& McArthur, J. W. (2005). The millennium project: A plan for meeting the millennium development goals. The Lancet, 365(9456), 347-353. https://doi.org/10.1016/S0140-6736(05)70201-4

Sachs, J., Schmidt-Traub, G., Kroll, C., Lafortune, G., \& Fuller, G. (2018). SDG Index and Dashboards Report 2018. New York: Bertelsmann Stiftung and Sustainable Development Solutions Network (SDSN).

Sharma, P. N., \& Kim, K. H. (2013). A comparison of PLS and ML bootstrapping techniques in SEM: A Monte Carlo study. In New perspectives in partial least squares and related methods (pp. 201-208). New York, NY.: Springer. https://doi.org/10.1007/978-1-4614-8283-3_13

SSI. (2016). Sustainable Society Index. Retrieved from http://www.ssfindex.com/

Stapleton, L. M., \& Garrod, G. D. (2008). The commitment to development index: An information theory approach. Ecological Economics, 66(2-3), 461-467. https://doi.org/10.1016/j.ecolecon.2007.10.009

Swesi, R., El-Anis, I., \& Islam, M. M. (2020). Food insecurity coping strategies in conflict-affected Libya. Development in Practice, 1-15. https://doi.org/10.1080/09614524.2019.1694644

Syakur, M., Khotimah, B., Rochman, E., \& Satoto, B. (2018). Integration K-means clustering method and elbow method for identification of the best customer profile cluster (Vol. 336, No. 1, p. 012017). Paper presented at the IOP Conference Series: Materials Science and Engineering. IOP Publishing. https://doi.org/10.1088/1757-899X/336/1/012017

Talon, A., \& Curt, C. (2017). Selection of appropriate defuzzification methods: Application to the assessment of dam performance. Expert Systems with Applications, 70, 160-174. https://doi.org/10.1016/j.eswa.2016.09.004

Tan, R., Aviso, K., Huelgas, A., \& Promentilla, M. (2014). Fuzzy AHP approach to selection problems in process engineering involving quantitative and qualitative aspects. Process Safety and Environmental Protection, 92(5), 467-475. https://doi.org/10.1016/j.psep.2013.11.005

United Nations. (2019). The Sustainable Development Report. Retrieved from https://sdghub.com/project/sustainable-development-report-2019/

United Nations. (2020, April 24). The Sustainable Development Goals. Retrieved from https://sustainabledevelopment.un.org/?menu=1300

Van de Kerk, G., \& Manuel, A. R. (2008). A comprehensive index for a sustainable society: The SSI-the Sustainable Society Index. Ecological Economics, 66(2-3), 228-242. https://doi.org/10.1016/j.ecolecon.2008.01.029

Wang, Y.-M., \& Chin, K.-S. (2009). A new data envelopment analysis method for priority determination and 
group decision making in the analytic hierarchy process. European Journal of Operational Research, 195(1), 239-250. https://doi.org/10.1016/j.ejor.2008.01.049

Wątróbski, J., Jankowski, J., Ziemba, P., Karczmarczyk, A., \& Zioło, M. (2019). Generalised framework for multi-criteria method selection. Omega, 86, 107-124. https://doi.org/10.1016/j.omega.2018.07.004

Wu, J., \& Wu, T. (2012). Sustainability indicators and indices: an overview. In Handbook of sustainability management (pp. 65-86). https://doi.org/10.1142/9789814354820_0004

\section{Copyrights}

Copyright for this article is retained by the author, with first publication rights granted to the journal.

This is an open-access article distributed under the terms and conditions of the Creative Commons Attribution license (http://creativecommons.org/licenses/by/4.0/). 